Available online at https://jurnal.stmikroyal.ac.id/index.php/jurdimas

\title{
PEMBERDAYAAN MASYARAKAT TERKAIT PENGARUH OBAT HERBAL DAN UPAYA MENINGKATKAN MANAJEMEN HIPERTENSI
}

\author{
Athia Fidian ${ }^{1}$, Yunita Safitri ${ }^{{ }^{*}}$, Avinda Yunita S. ${ }^{1}$, Munawar ${ }^{1}$, Ravi Lukman H. ${ }^{1}$ \\ ${ }^{1}$ Ilmu Keperawatan, Universitas Muhammadiyah Magelang \\ ${ }^{2}$ Farmasi, Universitas Muhammadiyah Magelang \\ email: *Yunitasafitrii.99@gmail.com
}

\begin{abstract}
Hypertension is a chronic disease and the number one killer in the world. Hypertension can attack almost all groups of people around the world, where the number of people who experience hypertension is increasing from year to year. Efforts can be made to reduce the incidence, such as taking blood pressure measurements or health checks, counseling about hypertension and treatment or handling to lower blood pressure. The village of Danurejo, especially in the hamlet of Japunan, is ranked fourth and fourth for people with hypertension. Lack of knowledge about hypertension management is one of the causes. This activity aims to increase public knowledge about hypertension and control the increase in blood pressure with herbal plants that are proven to reduce blood pressure, namely cucumber and celery. The results of the analysis with a comparison table, the results obtained that there are changes between before and before the administration of herbal medicines and health education. The average before the measurement of blood pressure is smaller than before the intervention, thus showing the influence of the administration of herbal medicine and health education. The implications of giving herbal medicines and health education can be used to increase the knowledge of citizens regarding hypertension management, so as to improve the quality of life of the elderly.
\end{abstract}

Keywords: hypertension; hypertension management; herbal drug therapy

Abstrak: Penyakit hipertensi merupakan penyakit bersifat menetap dan pembunuh nomor satu di dunia. Hipertensi dapat menyerang hampir semua golongan masyarakat diseluruh dunia, dimana jumlah masyarakat yang mengalami hipertensi semakin bertambah dari tahun ke tahun. Upaya yang dapat dilakukan untuk menurunkan angka kejadian hipertensi diantaranya melakukan kegiatan pengukuran tekanan darah atau pemeriksaan kesehatan, penyuluhan mengenai penyakit hipertensi dan pengobatan atau penanganan untuk menurunkan tekanan darah. Desa Danurejo terutama di dusun Japunan menjadi peringkat keempat untuk penderita hipertensi. Rendahnya pengetahuan tentang manajemen hipertensi menjadi salah satu penyebabnya. Kegiatan ini bertujuan untuk meningkatkan pengetahuan masyarakat tentang penyakit hipertensi dan mengontrol peningkatan tekanan darah dengan tanaman herbal yang sudah terbukti dapat menurunkan tekanan darah yaitu mentimun dan seledri. Hasil analisis dengan tabel perbandingan, didapatkan hasil bahwa terdapat perubahan antara sebelum dan sesudah pada pemberian obat herbal dan pendidikan kesehatan. Rata-rata sesudah pengukuran tekanan darah lebih kecil dari sebelum intervensi, sehingga menunjukan adanya pengaruh dari pemberian obat herbal dan pendidikan kesehatan. Implikasi pemberian obat herbal dan pendidikan kesehatan dapat di terapkan untuk meningakatkan pengetahuan warga terkait manajemen hipertensi, sehingga dapat meningkatkan kualitas hidup lansia.

Kata kunci: hipertensi; manajemen hipertensi; terapi obat herbal 
Available online at https://jurnal.stmikroyal.ac.id/index.php/jurdimas

\section{PENDAHULUAN}

Hipertensi merupakan penyakit yang ditandai dengan tekanan darah diatas normal, mengakibatkan suplai oksigen dan nutrisi yang dibawa oleh darah terhambat sampai ke jaringan tubuh yang membutuhkan (Mariyona, 2020). Di Indonesia maupun di dunia, hipertensi menjadi salah satu masalah kesehatan dan sifatnya menetap (Saputra \& Anam, 2016). Menurut World Health Organization (WHO) menyatakan bahwa penyakit hipertensi merupakan pembunuh nomor satu di dunia (Rahmaudina, Antri, Amalia, \& Kirnantoro, 2019). Menurut data WHO, sekitar 972 juta orang atau $26,4 \%$ di seluruh dunia mengidap hipertensi, angka ini kemungkinan akan meningkat di tahun 2025 menjadi $29,2 \%$. Dari 972 juta pengidap hipertensi, 639 berada di negara berkembang termasuk di Indonesia dan 333 juta sisanya berada di negara maju (Yonata, Satria, \& Pratama, 2016). Berdasarkan data WHO dinegara maju kawasan Afrika memegang posisi pertama penderita hipertensi sebesar40\%, Asia Tenggara $36 \%$ dan di Kawasan Amerika sebesar 35\%. Menurut Riset Kesehatan Dasar (Riskesdas) 2018 menyatakan bahwa jumlah penderita hipertensi di Indonesia mengalami peningkatan dari tahun 2013 sampai 2016 sebesar 32,4\% (Rahmaudina et al., 2019). Menurut data Dinas Kesehatan Provinsi Jawa Tengah tahun 2017, hipertensi di Jawa Tengah memiliki peringkat pertama dengan presentase sebesar 55\%. Di Kota Magelang pada tahun 2014 presentasinya sebesar 99,51\% (Nurhayati \& Fibriana, 2019). Hipertensi pada orang dewasa dengan prevalensi $6-15 \%$, sedangkan $50 \%$ diantaranya tidak menyadarinya sehingga mereka cenderung menjadi hipertensi berat. Secara umum hipertensi dapat meningkatnya risiko terhadap stroke, kerusakan ginjal, serangan jantung, dan aneurisma gagal jantung (Saputra \& Anam, 2016).

Hipertensi Sistolik Terisolasi (HTS) merupakan hipertensi yang sebagian besar pada lansia, peningkatan tekanan sistolik menyebabkan timbulnya stroke dan infark myocard meskipun tekanan diastoliknya dalam batas normal (isolated systolic hypertension). Banyak faktor penyebab hipertensi pada lansia salah satunya faktor usia, dimana semua fungsi dari system tubuh sudah mengalami penurunan fungsi, seperti pernafasan, neurologi, system kardiovaskuler, musculoskeletal, dan sebagainya (Yuliani, Achyar, \& Rofiqoch, 2020). Pola hidup tidak sehat pada orang yang memiliki riwayat penyakit hipertensi seperti alkoholis, obesitas, gula darah tinggi, kurang serat, konsumsi garam berlebih, mengkonsumsi tembakau, lemak darah tinggi dan stress, konsumsi tinggi lemak, kurang olahraga, akan memperberat resiko komplikasi seperti, mengakibatkan payah gagal ginjal, stroke, jantung, dan infark miokardium (Mariyona, 2020). Gejala pada hipertensi seringkali tidak ada, sementara darah yang terusmenerus tinggi dalam jangka waktu lama dapat menimbulkan komplikasi bahkan tak jarang dapat menyebabkan kematian mendadak. Oleh sebab itu, hipertensi perlu di deteksi dini dengan pemeriksaan tekanan darah secara rutin (Saputra \& Anam, 2016).

Menurut Mangendai, Rompas, and Hamel (2017), pada penelitiannya menjelaskan bahwa hipertensi merupakan penyakit yang tidak dapat disembuhkan tetapi harus selalu dikontrol agar tidak terjadi komplikasi yang dapat berujung pada kematian. Salah satu bentuk kegiatan yang dapat dilakukan untuk pengontrolan tekanan darah dengan memberikan pendidikan kesehatan 
Available online at https://jurnal.stmikroyal.ac.id/index.php/jurdimas

kepada penderita hipertensi. Penderita hipertensi di desa Danurejo khususnya di Dusun Jappunan belum memahami dengan benar tentang upaya preventif, promotif dan kuratif terhadap penyakit hipertensi. Menurut (Munica, Ulya, and Fakhry, 2017), pada penelitiannya menjelaskan bahwa manajmen hipertensi juga sangat penting karena manajemen hipertensi merupakan salah satu hal yang dapat dilakukan sebagai upaya mencegah terjadinya komplikasi pada penyakit lain. Pengetahuan masyarakat mengenai manajemen hipertensi saat ini masih kurang, salah satu cara yang dapat digunakan untuk meningkatkan pengetahuan seseorang yaitu dengan memberikan pendidikan. Pendidikan kesehatan merupakan suatu proses yang untuk mengajak orang lain, baik individu, kelompok atau masyarakat agar melaksanakan perilaku hidup sehat (Wijaya, Oktavidiati, \& Fredrika, 2019).

Selain itu, perlu juga dilakukan cara pengendalian hipertensi menggunakan terapi non farmakologias yaitu pengobatan secara herbalis. Pemanfaatan herbal untuk pemeliharaan kesehatan dan gangguan penyakit perlu dikembangkan, dengan mengacu pada konsep kembali ke alam yang banyak terdapat di masyarakat seperti mentimun dan seledri yang telah dipercaya oleh masyarakat dapat menurunkan tekanan darah (Lakai, 2014). Di kalangan masyarakat umum, mentimun dan seledri sering juga digunakan hanya sekedar perlengkapan hidangan maupun dengan maksud khusus untuk tekanan darah, karena terdapat kandungan pada mentimun dan seledri yang mampu membantu menurunkan tekanan darah. Telah terbukti bahwa kandungan yang ada pada mentimun seperti kalium (potassium), magnesium, dan fosfor efektif dalam menurunkan tekanan darah (Lakai, 2014). Pada penelitian
(Donna, Wijaya, Syahid, Karine, \& Handini, 2018) kandungan yang terdapat pada daun seledri dapat menurunkan tekanan darah tinggi diantaranya flavonoid, saponin, tanin 1\%, minyak asiri 0,033\%, flavo-glukosida (apiin), apeginin, fitosterol, kolin, lipase, pthalides, asparagine, zat pahit, vitamin (A, B dan C), aigenin dan alkaloid.

Oleh karena itu, pengabdian yang bertujuan untuk meningkatkan pengetahuan serta pengontrol peningkatan tekanan darah pada masyarakat yang beresiko mengalami hipertensi. Agar tingkat pengetahuan warga tentang manajemen hipertensi dapat meningkat terhadap terapi mandiri untuk menurunkan hipertensi. Dan mengetahui mentimun dan seledri maka dapat digunakan sebagai media pengobatan non farmakologis.

\section{METODE}

Kegiatan pengabdian kepada masyarakat ini dilakukan pendidikan kesehatan dengan dua topik, yaitu Konsep dasar Hipertensi, Terapi Komplementer (tanaman herbal). Sebelum pelaksanaan pendidikan kesehatan, peserta diminta mengisi kuisoner untuk mengukur beberapa aspek, begitu pula setelah dilakukan pendidikan kesehatan untuk mengevaluasi keberhasilan dari kegiatan yang dilakukan. Aspek yang diukur adalah Pengetahuan dan pola gaya hidup dalam manajemen hipertensi, dan intervensi sesudah dan sebelum terapi obat herbal. selain dengan ceramah, peserta akan diberikan pendampingan pembuatan obat herbal dilakukan secara langsung kepada peserta dengan mempraktekkannya.

Pelaksanaan dilakukan dengan 7 peserta yang berlokasi di dusun Japunan 
Jurdimas (Jurnal Pengabdian Kepada Masyarakat) Royal

Vol. 4 No. 3, September 2021, hlm. 231 - 238

ISSN 2614-7912 (Print)

DOI: https://doi.org/10.33330/jurdimas.v4i3.984

ISSN 2622-3813 (Online)

Available online at https://jurnal.stmikroyal.ac.id/index.php/jurdimas

desa Danurejo kecamatan Mertoyu dan dari rumah ke rumah peserta serta tempat melakukan pendidikan kesehatan adalah lembar kuesioner, pencatatan dan ten- simeter digital. Analisa data yang digunakan dalam penelitian ini adalah paired $t$ test dan analisis unvariat.

Tabel 1. Karakteristik umur

\begin{tabular}{|c|c|c|c|c|c|c|c|c|c|c|}
\hline \multirow{3}{*}{\multicolumn{2}{|c|}{$\begin{array}{l}\text { Rerata Sistolik dan } \\
\text { Diastolik Sebelum } \\
\text { dan Sesudah } \\
\text { Intervensi }\end{array}$}} & \multicolumn{4}{|c|}{ Paired Samples Statistics } & \multicolumn{5}{|c|}{ Report } \\
\hline & & \multirow{3}{*}{ Mean } & \multirow{3}{*}{$\mathrm{N}$} & \multirow{3}{*}{$\begin{array}{l}\text { Std. } \\
\text { Deviatio } \\
\text { n }\end{array}$} & \multirow{3}{*}{$\begin{array}{l}\text { Std. } \\
\text { Error } \\
\text { Mean }\end{array}$} & \multicolumn{5}{|c|}{ Umur Peserta } \\
\hline & & & & & & \multirow{6}{*}{$\begin{array}{c}\text { Umur } \\
\text { Peserta }\end{array}$} & $\begin{array}{c}\text { Jenis Ke- } \\
\text { lamin }\end{array}$ & Mean & $\mathrm{N}$ & $\begin{array}{l}\text { Std. } \\
\text { Devi }\end{array}$ \\
\hline & & & & & & & & & & $\mathrm{n}$ \\
\hline \multirow{4}{*}{$\begin{array}{c}\text { Pair } \\
1\end{array}$} & PreSistolik & 165.14 & 7 & 12.642 & 4.778 & & Laki-laki & 73 & 1 & . \\
\hline & PostSistolik & 135.00 & 7 & 6.164 & 2.330 & & Perempuan & 62.17 & 6 & $\begin{array}{c}9.02 \\
0\end{array}$ \\
\hline & PreDiastolik & 90.71 & 7 & 12.311 & 4.653 & & Total & & & \\
\hline & PostDiastolik & 77.71 & 7 & 8.538 & 3.227 & & & 63.71 & 7 & 9.196 \\
\hline
\end{tabular}

Tabel 2. Nilai sig

\begin{tabular}{|c|c|c|c|c|c|c|c|c|c|}
\hline \multirow{4}{*}{\multicolumn{2}{|c|}{$\begin{array}{l}\text { Perbedaan Sistolik } \\
\text { Sebelum dan } \\
\text { Sesudah Intervensi }\end{array}$}} & \multicolumn{8}{|c|}{ Paired Samples Test } \\
\hline & & \multicolumn{8}{|c|}{ Paired Differences } \\
\hline & & \multirow[t]{2}{*}{ Mean } & \multirow[t]{2}{*}{$\begin{array}{l}\text { Std. De- } \\
\text { viation }\end{array}$} & \multirow[t]{2}{*}{$\begin{array}{l}\text { Std. } \\
\text { Error } \\
\text { Mean }\end{array}$} & \multicolumn{2}{|c|}{$\begin{array}{l}95 \% \text { Confidence } \\
\text { Interval of the } \\
\text { Difference }\end{array}$} & \multirow[t]{2}{*}{$\mathrm{t}$} & \multirow[t]{2}{*}{$\mathrm{df}$} & \multirow[t]{2}{*}{$\begin{array}{c}\text { Sig. } \\
\text { (2-tailed) }\end{array}$} \\
\hline & & & & & Lower & Upper & & & \\
\hline $\begin{array}{c}\text { Pair } \\
1\end{array}$ & $\begin{array}{l}\text { PreSistolik - } \\
\text { PostSistolik }\end{array}$ & 30.143 & 16.537 & 6.250 & 14.849 & 45.437 & 4.823 & 6 & 0.003 \\
\hline
\end{tabular}

Tabel 3. Diastolic

\begin{tabular}{|c|c|c|c|c|c|c|c|c|}
\hline \multirow{4}{*}{$\begin{array}{c}\text { Perbedaan } \\
\text { Diastolik Sebelum } \\
\text { dan Sesudah } \\
\text { Intervensi }\end{array}$} & \multicolumn{8}{|c|}{ Paired Samples Test } \\
\hline & \multicolumn{8}{|c|}{ Paired Differences } \\
\hline & \multirow[t]{2}{*}{ Mean } & \multirow[t]{2}{*}{$\begin{array}{c}\text { Std. } \\
\text { Deviation }\end{array}$} & \multirow[t]{2}{*}{$\begin{array}{l}\text { Std. } \\
\text { Error } \\
\text { Mean }\end{array}$} & \multicolumn{2}{|c|}{$\begin{array}{l}95 \% \text { Confidence } \\
\text { Interval of the } \\
\text { Difference }\end{array}$} & \multirow[t]{2}{*}{$\mathrm{t}$} & \multirow[t]{2}{*}{$\mathrm{df}$} & \multirow[t]{2}{*}{$\begin{array}{c}\text { Sig. } \\
\text { (2-tailed) }\end{array}$} \\
\hline & & & & Lower & Upper & & & \\
\hline $\begin{array}{l}\text { PreDiastolik- } \\
\text { PostDiastolik }\end{array}$ & 13.000 & 12.179 & 4.603 & 1.736 & 24.264 & 2.824 & 6 & 0.030 \\
\hline
\end{tabular}


Available online at https://jurnal.stmikroyal.ac.id/index.php/jurdimas

Tabel 4. Tingkat pengetahuan sebelum diberikan pendidikan

\begin{tabular}{clcccc}
\hline $\begin{array}{c}\text { Tingkat Pengetahuan } \\
\text { Sebelum }\end{array}$ & Frequency & Percent & Valid Percent & $\begin{array}{c}\text { Cumulative Per- } \\
\text { cent }\end{array}$ \\
\hline \multirow{3}{*}{ Valid } & Baik & 4 & 57 & 57.1 & 57.1 \\
\cline { 2 - 6 } & Cukup Baik & 3 & 43 & 42.9 & 100 \\
\cline { 2 - 6 } & Total & 7 & 100 & 100 & \\
\hline
\end{tabular}

Tabel 5. Tingkat pengetahuan sesudah diberikan pendidikan

Tingkat Pengetahuan Sesudah

Frequency Percent Valid Percent Cumulative Percent

\begin{tabular}{llllll}
\hline Valid & Sangat Baik & 7 & 100.0 & 100.0 & 100.0 \\
\hline
\end{tabular}

\section{PEMBAHASAN}

Berdasarkan data karakteristik peserta berdasarkan umur yang di tampilkan pada Tabel 1 diketahui ratarata usia peserta adalah 63.71 dengan jenis kelamin terbanyak adalah berjenis kelamin perempuan. Hipertensi merupakan salah satu penyakit degenerative, tekanan darah bertambah secara perlahan dengan bertambahnya umur. Risiko hipertensi pada populasi $\geq 55$ tahun. Umur diatas 60 tahun 50-60\% mempunyai tekanan darah lebih tinggi atau sama dengan 140/90 $\mathrm{mmHg}$ hal ini merupakan pengaruh degenerisasi yang terjadi pada orang yang bertambah usianya. Ditinjau dari segi jenis kelamin antara perempuan dan laki-laki, secara umum kaum perempuan lebih banyak menderita hipertensi dibandingkan dengan laki-laki (Asmawati, Purwati, \& Handayani, 2015).

Nilai sig. (2-tailed) pada Tabel 2 untuk sistolik 0.003 dan dan Tabel 3 diastolic 0.030 yang artinya $<0.05$ maka dapat disimpulkan bahwa terdapat perbedaan yang nyata antara hasil pengukuran tekanan darah sebelum dan sesudah diberikan terapi obat herbal, sehingga dapat disimpulkan pemberian terapi obat herbal dapat menurunkan tekanan darah. Kemudian untuk Nilai t hitung pada sistolik (4.823) > t tabel (2.446) dan diastolik hitung (2.824) $>\mathrm{t}$ tabel (2.446) ada perbedaan signifikan antara pengukuran tekanan darah sebelum dan sesudah uji, sehingga dapat disimpulkan terapi obat herbal memiliki efek antihipertensi.

Tingkat pengetahuan sebelum diberikan pendidikan kesehatan kategori baik 4 orang $(57.1 \%)$ dan cukup baik 3 orang $(42.9 \%$ ) dapat dilihat pada Tabel 4. Sedangkan Tingkat pengetahuan sesudah diberikan pendidikan kesehatan sangat baik yaitu 7 orang dengan presentase $100 \%$ (dapat dilihat pada Tabel 5).

Diminggu pertama dilakukan Pelaksanaan pada tanggal 18 Oktober 2020 secara door to door Harapan dari kegiatan ini adalah Tercapainya tujuan, agar masyarakat sekitar dapat menerima keberdaan tim Pengabdian dan mengikuti setiap program kerja yang akan dilakukan oleh tim pengabdian di Dusun Japunan mulai dari kegiatan pengkajian penyakit hipertensi, pendidikan kesehatan tentang hipertensi, pelatihan pembuatan terapi 
Available online at https://jurnal.stmikroyal.ac.id/index.php/jurdimas

nonfarmakologi dengan memanfaatkan tanaman seledri dan mentimun.

Persentase lansia penderita hipertensi di desa Danurejo terutama di dusun Japunan termasuk tinggi. Oleh karena itu tim pengabdian masyarakat melakukan kegiatan penyuluhan, manajemen hipertensi, dan pembuatan obat herbal. Sebelum dilakukan penyuluhan dilakukan pengukuran tekanan darah terlebih dahulu dan dilakukan selama 2 minggu, minggu pertama sebelum diberikan terapi obat herbal dan minnggu kedua setelah diberikan terapi obat herbal. Selanjutnya diberikan penyuluhan tentang manajemen hipertensi ini bertujuan untuk meningkatkan pengetahuan dan sikap lansia dalam melakukan manajemen hipertensi dalam kehidupan seharihari. Pendidikan kesehatan yang dilakukan diberikan ceramah dengan media belajar lembar balik serta leaflet yang dibuat untuk mempermudah peserta dalam memahami materi terkait hipertensi meliputi materi dasar seperti pengertian, faktor resiko, tanda dan gejala, komplikasi, pengendalian hipertensi, dan makanan untuk penderita hipertensi.

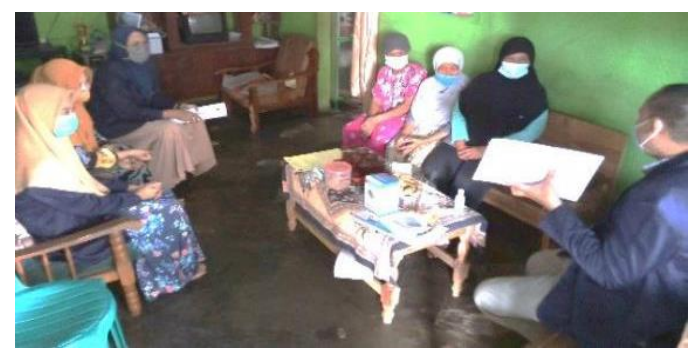

Gambar 1. Penyuluhan tentang manajemen hipertensi

Kegiatan selanjutnya pemanfaatan tanaman obat yaitu mentimun dan seledri untuk menurunkan tekanan darah tinggi. dilakukan pendampingan kepada peserta dalam pembuatan jus mentimun dan rebusan air seledri sesuai dengan dosis yang telah ditetapkan. Kegiatan ini membuat lansia mampu memahami dan menerapkan cara pembuatan jus mentimun dan rebusan daun seledri dengan baik dan benar sebagai salah satu terapi nonfarmakologis untuk pengontrolan tekanan darah. Pemberian jus mentimun dan rebusan air seledri dengan diiringi perubahan pola hidup yang sehat dengan mengkonsumsi makanan rendah lemak dan kolesterol, seperti mengkonsumsi sayur-sayuran atau buah-buah segar akan lebih berpengaruh dalam menurunkan tekanan darah tinggi.

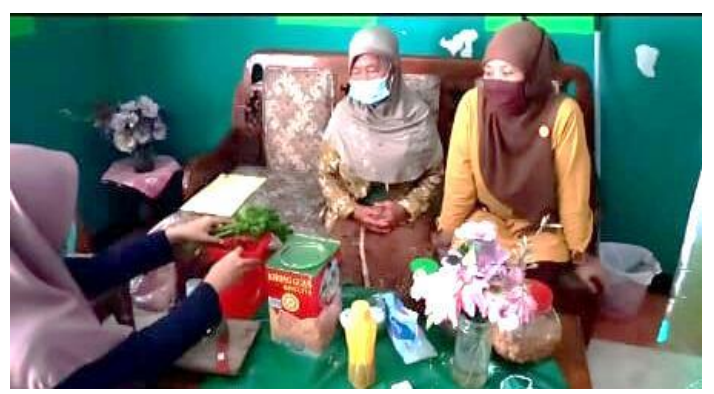

Gambar 2. Pendampingan pembuatan jus mentium dan air rebusan seledri

Secara deskriptif ada perbedaan secara signifikan antara intervensi sebelum dan sesudah pengukuran tekanan darah. Mean merupakan nilai rata-rata dari pengukuran tekanan darah sebe-lum dan sesudah intervensi terapi obat herbal yaitu rata-rata presistolik 165.14 dan postsistolik 135.00 , sedangkan prediastolik 90.71 dan postdiastolik 77.71. Nilai $\mathrm{N}$ merupakan jumlah sample yang dipakai yaitu 7. Dari hasil rata-rata pada tabel diatas sistolik maupun diastolic menunjukan hasil yang bagus karena hasil rata-rata sesudah pengukuran tekanan darah lebih kecil dari sebelum intervensi, sehingga menunjukan adanya pengaruh dari pemberian obat herbal. Sementara itu, untuk nilai sig. (2-tailed) pada tabel untuk sistolik 0.003 dan diastolic 0.030 yang artinya $<0.05$ maka dapat disimpulkan bahwa terdapat perbe- 
Available online at https://jurnal.stmikroyal.ac.id/index.php/jurdimas

daan yang nyata antara hasil pengukuran tekanan darah sebelum dan sesudah diberikan terapi obat herbal, sehingga dapat disimpul-kan pemberian terapi obat herbal dapat menurunkan tekanan darah. Kemudian untuk Nilai t hitung pada sistolik (4.823) > t tabel (2.446) dan diastolik hitung (2.824) > t tabel (2.446) ada perbedaan signifikan antara pengukuran tekanan darah sebelum dan sesudah uji, sehingga dapat disimpulkan terapi obat herbal memiliki efek antihiperten-si.

Pendidikian kesehatan ini diikuti oleh 7 orang, untuk mengamati tingkat pengetahuan dan aktivitas pola hidup sebelum dan sesudah diberikan pendidikan kesehatan dan simulasi manajemen hipertensi didapatkan data sebagai berikut. Dilihat dari tabel tingkat pengetahuan sebelum diberikan pendidikan kesehatan dengan kategori baik yaitu sebanyak 4 orang $(57.1 \%)$ dan cukup baik 3 orang (42.9\%). Berdasarkan data tersebut perlunya pendidikaan kesehatan bagi peserta, sehingga perlunya pendidikan kesehatan terkait hipertensi untuki meningkatkan tingkat pengetahuan peserta. Sedangkan setelah dilakukan pendidikan kesehatan tekait hipertensi ketujuh peserta memiliki peningkatan yang sangat baik. Sehingga dapat disimpulkan bahwa peserta yang mengikuti pendidikan kesehatan terkait hipertensi sudah memahami tentang penanganan dan pencegahan hipertensi. Kuesioner setelah diberikan pendidikan kesehatan ini dapat dijadikan evaluasi yang sesuai setelah dilakukan pendidikan kesehatan. Hal tersebut sesuai dengan penelitian yang telah dilakukan oleh (Ulya, Iskandar, \& Asih 2017) bahwa pendidikan kesehatan dapat meningkatkan pengetahuan seseorang. Di dalam penelitian ini didapatkan perbedaan yang bermakna pada skor manajemen hipertensi sebelum dan sesudah diberikan pendidikan kesehatan.
Disamping itu, kegiatan pendidikan kesehatan juga didukung dengan adanya alat bantu dalam mempresentasikan pendidikan kesehatan, sehingga membantu dan memudahkan dalam penyampaiannya.

\section{SIMPULAN}

Nilai $\mathrm{t}$ hitung pada sistolik (4.823) > t tabel (2.446) dan di-astolik hitung (2.824) > t tabel (2.446) ada perbedaan signifikan antara penguku-ran tekanan darah sebelum dan sesudah uji, sehingga dapat disimpulkan terapi obat herbal memiliki efek antihipertensi. Pengabdian kepada Masyarakat di dusun Japunan desa Danurejo dalam manajemen dan terapi obat herbal yang diberikan kepada peserta telah mencapai tingkat keberhasilan sesuai dengan yang direncanakan.

\section{DAFTAR PUSTAKA}

Asmawati, N., Purwati, \& Handayani, R. S. (2015). Efektivitas Rebusan Seledri dalam Menurunkan Tekanan Darah pada Lansia Penderita Hipertensi di Posyandu Lansia Kelurahan Pajar Bulan Kecamatan Way tenong Lampung Barat. Jurnal Kesehatan, 6(2), 130-136.

Donna, B. P., Wijaya, L. S., Syahid, M. A., Karine, S. W., \& Handini, Y. S. (2018). Ekstrak Daun Seledri (Ex-Sel) dalam Kemasan Ekonomis Siap Minum untuk Terapi Hipertensi. Jurnal Abdi Insani, 5(2), 1-6. doi: 10.29303/abdiinsani.v5i2.171

Lakai, N. (2014). Pengaruh Konsumsi Mentimun terhadap Penurunan 
Tekanan Darah pada Lansia di Panti Sosial Tresna Werdha Gau Mabaji Kabupaten Gowa. Makassar. doi: 10.1016/j.bbapap.2013.06.007

Mangendai, Y., Rompas, S., \& Hamel, S. R. (2017). Faktor-Faktor yang Berhubungan dengan Kepatuhan Berobat Pada Pasien Hipertensi di Puskesmas Ranotana Weru. Jurnal Keperawatan UNSRAT, 5(1), 1-8.

Mariyona, K. (2020). Penurunan Tekanan Darah Penderita Hipertensi dengan Pemberian Air Rebusan Seledri (Apium graveolens L). MIKIA, 4(1), 1-6.

Munica, R. D., Ulya, M., \& Fakhry, M. (2017). Analisis Strategi Pengembangan Industri Jamu Tradisional Di Kabupaten Bangkalan - Madura. Agrointek, 11(2), $84 . \quad$ doi: 10.21107/agrointek.v11i2.3057

Nurhayati, L., \& Fibriana, N. (2019). Dukungan Keluarga Terhadap Kepatuhan Kontrol Pengobatan Pasien Pipertensi. Jurnal Keperawatan, 5(2), 63-69.

Rahmaudina, T., Antri, Amalia, N. R., \& Kirnantoro. (2019). Studi Kasus: Studi Dokumentasi Ketidakefektifan Manajemen Kesehatan Keluarga dengan Hipertensi. Journal of Chemical Information and Modeling, 53(9), 1689-1699.

Saputra, O., \& Anam, K. (2016). Gaya Hidup sebagai Faktor Risiko
Hipertensi pada Masyarakat Pesisir Pantai Life Style as Risk Factor of Hypertension in Seaboard Community. Majority, 5(3), 118-123.

Ulya, Z., Iskandar, A., \& Asih, F. T. (2017). Pengaruh Pendidikan Kesehatan dengan Media Poster Terhadap Pengetahuan Manajemen Hipertensi Pada Penderita Hipertensi. Jurnal Keperawatan Soedirman, 12(1), 38-46. doi: 10.20884/1.jks.2017.12.1.715

Wijaya, A. K., Oktavidiati, E., \& Fredrika, L. (2019). Pemanfaatan Daun Seledri Dipekarangan Rumah Untuk Pengontrolan Tekanan Darah Dan Membantu Perekonomian Keluarga. Jurnal Pengabdian Masyarakat Bumi Raflesia, 2(2), 138-147. doi: 10.36085/jpmbr.v2i2.441

Yonata, A., Satria, A., \& Pratama, P. (2016). Hipertensi sebagai Faktor Pencetus Terjadinya Stroke. Majority, 5(3), 17-21.

Yuliani, D. A., Achyar, K., \& Rofiqoch, I. (2020). IbM Pendidikan Kesehatan Hipertensi dan Pengukuran Kolesterol Hipertensi merupakan salah satu penyakit tidak menular yang menjadi masalah kesehatan yang serius . Hipertensi pada umumnya jauh diatas normal, maka hipertensi diam-diam atau the silent killer. Jurnal ABDIMAS-HIP, 1(2), 6468. 